reached equivalence with singletons for measures of IQ by age 6 . The age-to-age predictive correlations followed the typical pattern of becoming smaller as the age span increased, so that scores in the first two years had only limited predictive power for 6-year IQ. However, these correlations were higher than had previously been reported, and they suggested a greater continuity in preschool mental development than is usually acknowledged. Sex differences were also evident in the measures of age-to-age continuity.

When a zygosity analysis was performed, MZ twins were found to be significantly more concordant than DZ twins for the measures of mental development at each age. MZ twins were also more concordant for the spurts and lags in mental development up to age 5. By that age, the measures of intelligence had stabilized to the point where each twin maintained a consistent IQ score from one year to the next, and the spurt/lag factor was no longer significant.

Parent's education and socioeconomic status gave modest positive correlations $(r=$ o.3o) with the twins' IQ scores at age 6. The overall pattern of results pointed to the genetic blueprint as the principal determinant of childhood mental development for the broad range of home environments represented in this study.

Ronald S. Wilson, Ph.D., Medical-Dental Research Bldg. Rm. i I H, P.O. Box I055, Louisville, Kentucky 4020I, USA

\section{RELATIONAL BEHAVIORS AND BODY IMAGE IN TWINS}

\section{F. GACCIAGUERRA}

The Piancavallo Auxologic Center, Milan, Italy

A twin study has been carried out in order to contribute to a better understanding of the following problems:

(1) Whether zygosity affects body image, either in terms of ambiguity or reinforcement, and self perception with respect to the cotwin's perception.
(2) Whether inadequacy of body image is associated to troubles in size perception and to a reduced utilization of somatic terms.

(3) Whether body image affects size perception to a greater extent through visual and tactile channels.

(4) Whether the typical relation existing between $\mathrm{MZ}$ cotwins affects the ability to catch the relations between objects.

(5) Whether the above-mentioned problems are affected by the variable "dominance".

Prof. F. Cacciaguerra, Centro Auxologico, Corso Magenta 42, 20123 Milano, Italy

\section{PSYCHOPATHOLOGIC PROBLEMS IN TWINS DURING GHILDHOOD}

\author{
P. BERNABEI, G. LEVI
}

Department of Child Neuropsychiatry, University of Rome, Italy

Some psychopathologic problems occurring during childhood in twins are discussed from the point of view of mental health.

On the basis of case histories of twins affected by neurologic or psychiatric disorders some typical situations have been examined:

(I) Psychopathologic problems arising from perinatal death of the cotwin;

(2) Psychopathologic problems arising from the death of the cotwin during late childhood;

(3) Psychopathologic problems arising in the pair from organic or neuropsychiatric event in one of the twins;

(4) Psychopathologic problems of the twins due to disorders of personal identity and the interaction between the twins.

The cases are analyzed from a psychodynamic point of view, in relation to the development of personality in the twins, and from a psychosocial point of view, in relation to the cultural stereotype of the twins. The problems of mental health of the twins during the socialization process and in the context of parental dynamics are considered in relation to this clinical analysis.

Dott.ssa P. Bernabei, Istituto di Neuropsichiatria Infantile, Via dei Sabelli 108, oor85 Roma, Italy 